\title{
Sexual behaviour of rams: male orientation and its endocrine correlates
}

\author{
J. A. Resko ${ }^{1}$, A. Perkins ${ }^{2}$, C. E. Roselli ${ }^{1}$, J. N. Stellflug ${ }^{3}$ \\ and F. K. Stormshak ${ }^{4}$ \\ ${ }^{1}$ Department of Physiology and Pharmacology, School of Medicine, Oregon Health Sciences \\ University, Portland, OR 97201-3098, USA; ${ }^{2}$ Department of Psychology, Carroll College, Helena, \\ MAO 59625, USA; ${ }^{3}$ US Sheep Experimentation Station, Dubois, ID 83425, USA; and \\ ${ }^{2}$ Department of Animal Sciences, Oregon State University, Corvallis, OR 97331-6702, USA
}

\begin{abstract}
The components of heterosexual behaviour in rams are reviewed as a basis for understanding partner preference behaviour. A small percentage of rams will not mate with oestrous females and if given a choice will display courtship behaviour towards another ram in preference to a female. Some of the endocrine profiles of these maleoriented rams differ from those of heterosexual controls. These differences include reduced serum concentrations of testosterone, oestradiol and oestrone, reduced capacity to produce testosterone in vitro, and reduced capacity to aromatize androgens in the preoptic-anterior hypothalamus of the brain. Our observation that aromatase activity is significantly lower in the preoptic-anterior hypothalamic area of male-oriented rams than in female-oriented rams may indicate an important neurochemical link to sexual behaviour that should be investigated. The defect in steroid hormone production by the adult testes of the male-oriented ram may represent a defect that can be traced to the fetal testes. If this contention is correct, partner preference behaviour of rams may also be traceable to fetal development and represent a phenomenon of sexual differentiation.
\end{abstract}

\section{Sexual Behaviour}

Sexual differentiation of the brain

Although the effects of androgen on the development of the reproductive tract and the external organs of reproduction were known previously for several species, early experiments using the guinea-pig as an experimental model expanded the 'hormonal theory' of sexual differentiation to include the brain (Phoenix et al., 1959). This landmark publication provided a rationale for behavioural scientists and neuroendocrinologists to study the effects of androgens and their metabolites in the developing fetus to ascertain the relationship between androgen action and the expression of heterosexual behaviour and gonadotrophin release in adulthood.

In general, the principles that govern the 'organizational' effects of androgen on the fetal brain, that is, permanent effects that carry over into the adult period, are similar to those proposed for the reproductive tract and the external organs of reproduction. In males, androgens secreted by the fetal testes act upon undifferentiated target tissues and produce a male phenotype (both anatomical and behavioural). The basic phenotype appears to be female and will remain female without the intervention of endogenous androgen. Females exposed to androgen during a 'critical' period for sexual differentiation will be androgenized permanently. Males deprived of androgen exposure during the 'critical period' regardless of the method, for example castration, use of drugs, or chemicals, will be feminized.

The principles described above for brain organization apply to a wide variety of mammalian species including sheep (Short, 1974). In sheep fetuses, the gonads differentiate into testes or ovaries by day 35 of gestation (Resko, 1985); the period of gestation is approximately 151 days. Testosterone

(a) 1999 Journals of Reproduction and Fertility Ltd 
can be quantified in the developing gonad on day 30 of gestation and its concentrations in testes increase with fetal age (Attal, 1969). Plasma obtained from sheep fetuses on day 70 of gestation contained significantly higher quantities of testosterone if it was obtained from male compared with female fetuses (Pomerantz and Nalbandov, 1975). This sex difference in testosterone concentrations probably occurred from day 35 (the day on which the fetal gonads differentiate) to day 60 , the period in which sexual differentiation of the brain can be controlled by exogenous androgen administration to the pregnant ewe (Short, 1974). Androgen effects on brains of male fetuses can be determined in at least two ways: by the repertoire of reproductive behaviours that are displayed in adulthood and by the pattern of gonadotrophins released in response to an oestrogen challenge (Short, 1974; Karsch and Foster, 1975). Typically, rams will pursue oestrous females and display courtship behaviour which terminates with ejaculation (Banks, 1964). Reproductive behaviours in rams can be seasonally dependent in temperate climates; therefore, time of year is an important consideration for testing male behaviours in sheep (Pepelko and Clegg, 1965). Neither female-nor male-oriented rams release surge amounts of gonadotrophin in response to an oestrogen challenge, which is an adequate trigger for gonadotrophin release in females (Short, 1974; Karsch and Foster, 1975; Perkins et al., 1995). Adult females, on the other hand, whose brains were not exposed to 'high' levels of androgen during the 'critical period' for sexual differentiation in the fetus, typically display oestrous behaviour and are receptive to the courtship behaviours of the male.

\section{Partner preference behaviour}

Partner preference behaviour can be defined as the sex of the partner toward which an individual directs behaviour of a sexual nature. If a male directs his sexual overtures towards a female, the male is classified as female-oriented. If, on the other hand, these behaviours are directed towards another male, the male is classified as male-oriented. In this review, we will not, by definition, consider the behaviour of anatomically feminized males, due to low amounts of androgen exposure during the critical period for sexual differentiation, and which display female (receptive) behaviours towards another male. Rather, we will discuss only males that possess the normal male anatomical phenotype yet choose another male over a female as a sexual partner.

A schematic representation of the phases and interrelationships of heterosexual behaviours is presented in Fig. 1. (Beach, 1976). Heterosexual behaviours of both sexes can be divided into four phases: attractive, appetitive, consummatory and postconsummatory (Beach, 1976). For a more detailed description of these phases, the reader should consult the review by Beach (1976). Generally, however, sexual attractiveness is an abstraction inferred from observations of the behaviour of males toward females. Appetitive behaviour of males such as approaching and investigating females probably depends on olfactory and visual cues. Consummatory responses that is, ejaculations, on the other hand, are associated with contact stimuli and secretions of the vagina. In the postconsummatory phase, the male temporarily loses the capacity to respond to the stimuli that initiated the sexual activity.

Male sexual performance depends upon the various stimuli provided by the female. The behavioural and nonbehavioural characteristics of a female that enable a ram to distinguish an oestrous ewe from one that is not in oestrus have been divided into the following categories: attractivity, proceptivity and receptivity. From observations of mating behaviour of sheep, one might conclude that rams, aggressively, seek out oestrous females and that the female plays only a minor role in this process. However, it has been shown that ewes in oestrus actively solicit males (proceptive behaviour) so that mating can be completed (Lindsay, 1961). Sexual receptivity in females can be defined as the response of the female to stimuli provided by the male. It is part of the consummatory phase. In ovariectomized ewes, receptivity can be induced by multiple injections of progesterone followed by a single dose of oestrogen (Lindsay, 1966) or by treatment with synthetic steroids and prostaglandins (Fitzgerald et al., 1985). It is possible that heterosexual behaviours in mammals follow a bell shaped curve. The sexual activity of most animals falls within two standard deviations of the central point of this curve (the mean). A small number of animals fall within three standard deviations of the mean. Those on the upper end of the curve represent high-libido males; those on the lower end of the curve possess little or no sexual drive. 


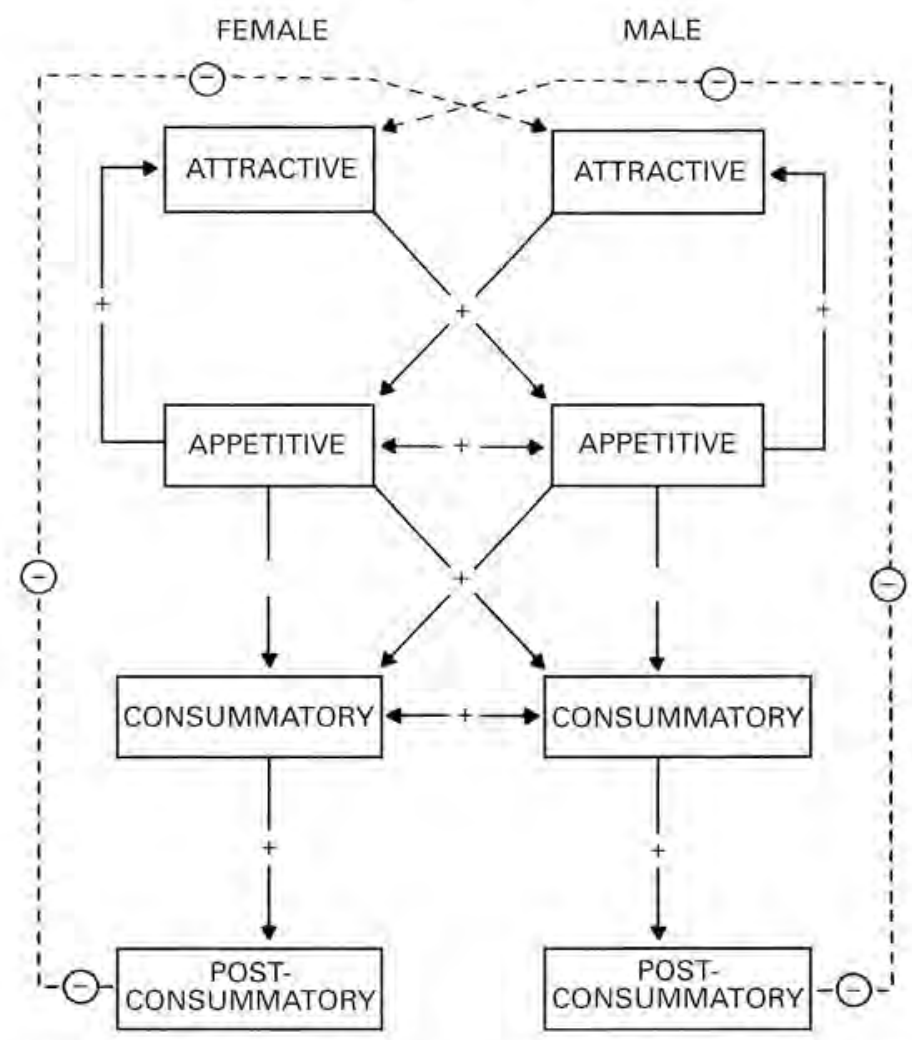

Fig. 1. Phases and interrelationships between a male and a female in heterosexual matings. $(-)$ indicates inhibition; $(+)$ indicates stimulation. (Reprinted from Beach, 1976 Hormones and Behavior 7 105-138, with permission).

Many species of vertebrate including humans with normal to high libido participate in maleoriented behaviour (Dagg, 1984). Male orientation of domestic rams, determined by preferential sexual contact with males over females, has been reported (Perkins and Fitzgerald, 1992; Zenchak et al., 1981). These behaviours are found not only in domesticated sheep but also in nondomesticated Bighom sheep (Geist, 1971). In wild populations, rams segregate into all male groups after maturity. The dominant male attempts copulation with the subordinate males. Most of the aggression in the group occurs between the subordinates directed towards the dominate ram(s). Subordinate rams that are not aggressive live peacefully within the group. Thus it appears that the submissive behaviour of the subordinate rams has some adaptive significance perhaps to reduce aggression within the all male group (Geist, 1971). The behaviour of the dominant male is not exclusively maleoriented, however, because dominate males, if given the opportunity, will mate with oestrous females. Males that display both male- and female-oriented behaviours have been identified in many animal species. This type of behaviour seems to be confounded with dominance. On the other hand, a small percentage of rams, in any given population, will be exclusively male-oriented. Thus, the domestic ram may be a useful model for investigating the physiological basis of partner preference because these latter males, if given a choice, will exhibit courtship behaviour towards a male rather than an oestrous female (Resko ef al., 1996).

The phenomenon of homosexual behaviour in men is not well understood but, as mentioned above for sheep, only a small percentage of men are truly male oriented, that is, are attracted only to men. Theories of aetiology range from defective parental nurturing (Freud, 1953) to differences in 
brain structure and chemistry between homosexual and heterosexual individuals (Dorner et al $l_{\text {, }}$ 1975; Gladue, 1984; Swaab and Hofman, 1990; Le Vay, 1991; Allen and Gorski, 1992). The influence of individual genetic make-up has also been considered. Homosexual behaviour correlates with inheritance of polymorphic markers on the $\mathrm{X}$ chromosome (Xq28 region) in men which has led to speculation regarding maternal inheritance of these behavioural characteristics (Hamer et al., 1993; Hu et al., 1995). The short arm of the $Y$ chromosome contains the sex-determining gene(s) which organizes the fetal testes (Page et al., 1987), the secretions of which play a major role in sexual differentiation. In early prophase I, the sex chromosomes condense to form a heterochromatic structure called the XY body (Solari, 1980) and there is evidence that genetic material can exchange between the $X$ and the $Y$ chromosome at this time (Freije et al., 1992). It is conceivable that in a small number of cases exchange of the sex-determining gene(s) from the $Y$ to the $X$ chromosome occurs. This exchange may affect normal organization of the fetal testes and the quantity and type of hormones that they produce with concomitant effects on brain development. Genetic control of sexual orientation has also been reported in Drosophila (Ryner et al., 1996).

\section{Role of the medial preoptic-anterior hypothalamic area in male sexul behaviour}

The medial preoptic-anterior hypothalamic area (MPOA) mediates male reproductive behaviours in many species. In rats (Heimer and Larsson, 1966; Giantonio et al., 1970; Ginton and Merari, 1977), cats (Hart et al, 1973), dogs (Hart, 1989), goats (Hart, 1986) and monkeys (Slimp et al., 1978), lesions of the MPOA interfere with normal male copulatory responses. A possible function of this area is that it is the sensory processor of sexual behaviours but not of sexual arousal (Giantonio et al, 1970; Everitt and Stacey, 1987). Animals with brain lesions cannot integrate information of a sexual nature thus resulting in defective copulatory behaviour (Heimer and Larsson, 1966; Everitt and Stacey, 1987). The relationship of the MPOA to partner preference behaviour is not well understood. Male ferrets, however, that have been treated with oestrogen and have bilateral lesions of the MPOA spend more time with stimulus males than do control males (Paredes and Baum, 1995).

\section{Role of in situ destrogen formation by netural tissue in male sextal behaviour}

Aromatase activity (the sum total of biochemical events that convert androgen to oestrogen) is relatively high in the MPOA of rodents compared with other parts of the brain (Roselli et al., 1985). It appears that the concentrations of this enzyme activity within the MPOA are important for the following reasons: (1) testosterone or oestradiol is capable of restoring male copulatory behaviour in castrated rats (Davidson, 1969); (2) testosterone is unable to maintain normal male sexual behaviour in animals treated with inhibitors of aromatization (Beyer et al., 1986). Similarly, sexual differentiation of the male brain during the 'critical period' is mediated by aromatization of androgen to oestrogen in some species (MacLusky and Naftolin, 1981). Treatment of rats during the 'critical period' for sexual differentiation of the brain with compounds that inhibit aromatization or are oestrogen antagonists prevents androgen-induced defeminization of the brain (McEwen et al., 1977; Sodersten, 1978) and differentiation of the sexually dimorphic nucleus in the preoptic area (Dohler et al, 1984). In a similar way, male ferrets require in situ oestrogen formation in the MPOA for differentiation of the sexually dimorphic nucleus (Baum et al., 1996). Male rats exposed to an aromatase inhibitor during the neonatal period showed a preference for stimulus males over oestrous females when tested in the early part of the dark phase of the light-dark cycle (Bakker et al.,1993).

\section{Endocrine Correlates of Partner Preference Behaviour in Rams}

In previous work (Resko et al., 1996), we studied partner preference behaviour in rams and correlated this behaviour with steroid concentrations in the systemic circulation, capacity of the testes to produce androgens and oestrogens, and brain aromatase activity. 
Rams used in this study were of Targhee, Rambouillet, Columbia and Polypay breeds. All rams were born in the spring lambing season (April and May). Rearing conditions have been described by Fitzgerald et al. (1993). Briefly, ewes and lambs grazed spring and summer ranges until weaning in August. At weaning, ram and ewe lambs were separated from the dams. Ram lambs were combined into all male groups of approximately $400-500$ animals. The ram lambs were kept on autumn range land, grazing for an additional 2 months, and then moved to a feedlot (November until April) where they received rations developed for growing animals. At one year of age, ram lambs were moved as a group onto spring ranges and kept through the summer and autumn. During this time, they were exposed only to natural changes in photoperiod and had no physical contact with females. Sexual behaviour of the rams was tested beginning at approximately 16 to 18 months of age.

\section{Preliminary tests}

From August to October of the second year of life, the sexual behaviours of these rams were tested. Rams were placed with three mature ovariectomized ewes in which oestrus was induced by exogenous hormone treatments as described by Fitzgerald et al. (1985). Each test was for 30 min and each ram was tested at least six times. Repeated tests revealed three groups of rams: those that mated with oestrous females repeatedly (female-oriented), those that mated with oestrous females occasionally but at least once (low libido males), those that did not mount oestrous females (potentially male-oriented).

After these tests were completed, the size of the male population reared together was reduced to 25-30 rams of mixed sexual preference. These animals were housed together in outdoor pens approximately $12 \mathrm{~m}^{2}$ and were not permitted physical contact with females, but females were housed in adjacent pens. Rams that would not mount oestrous females in the preliminary tests mentioned above, as well as female-oriented rams, mounted male pen-mates in the group setting.

\section{Preference tests}

Only rams that would not mount oestrous females in the preliminary tests satisfied the criterion for entrance into the sexual preference paradigm. A description of the method and apparatus used in the sexual preference tests have been described by Perkins and Fitzgerald (1992) and are shown in Fig. 2.

Briefly, in November and December of the second year of life, rams were exposed, simultaneously, to two restrained oestrous females and two males that were chosen at random for use. Rams that courted and mounted males in preference to females during a 30 min test that was repeated at least three times were classified as male-oriented. Using these procedures, we identified six males that would not mount females in the preliminary sexual tests, mounted males in a group setting, and mounted males in preference to females in the sexual preference tests. Male-oriented rams were given an additional preference test 5 days before they were killed at three and one-half years of age.

\section{Treatment of female-oriented controls}

During the breeding season of the second year of life (November and December), the seven, female-oriented rams were used as breeders and were housed with cyclic females in single-sire outdoor pens for this purpose. They remained with the females for 32 days after which they were returned to the all male group which contained male-oriented and low libido males from which they were taken. Female-oriented rams were tested with oestrous females for a 2 week period in August of the third year of life. Afterwards they were returned to their all male groups where they remained until they were killed along with the male-oriented rams in late October of the same year. 

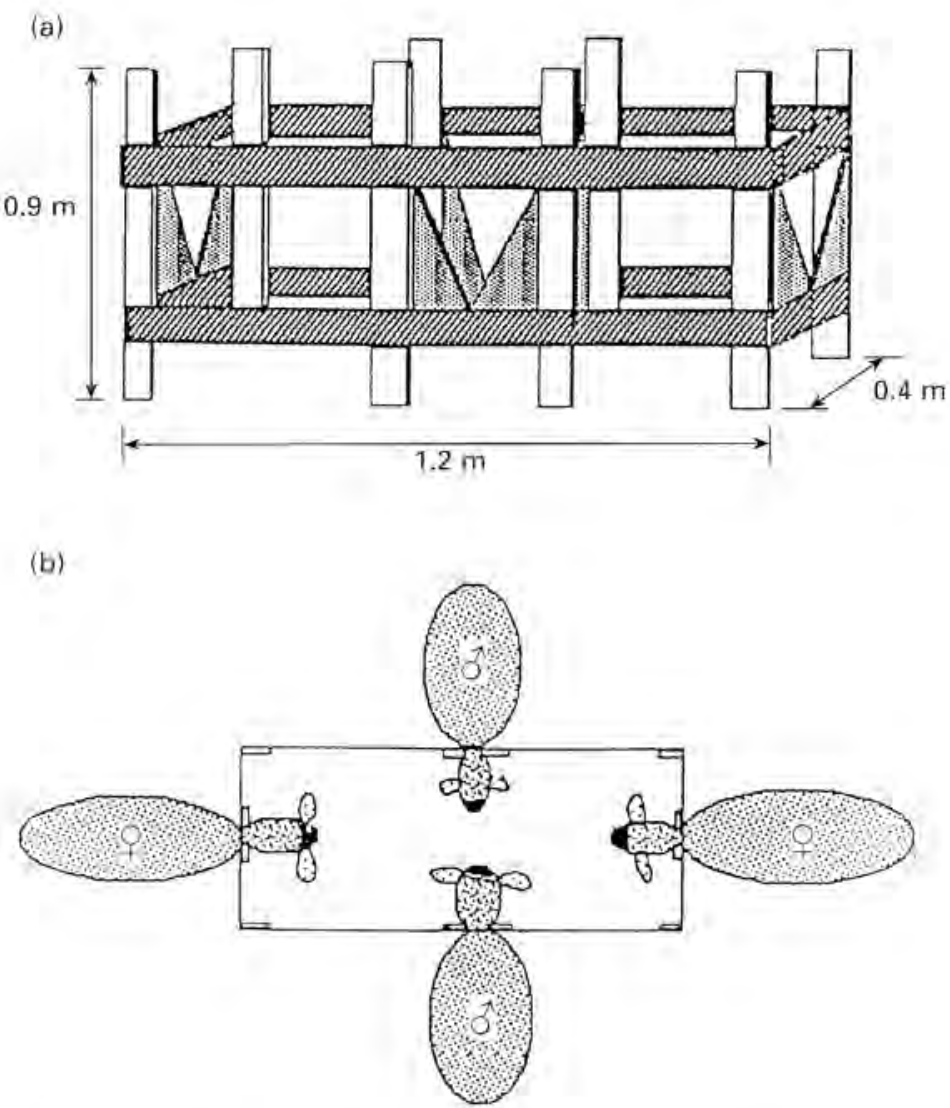

Fig. 2. A diagrammatic representation of the method used for sexual preference testing. The upper panel shows a diagram of a four-way stanchion for restraining test subjects. The lower panel demonstrates that oestrous females (and stimulus males) were restrained in the stanchion facing one another. (Reprinted from Perkins and Fitzgerald, 1992 Journal of Animal Science 70 1787-1794, with permission).

\section{Birth records}

Because it has been shown that rams born co-twin with males are sexually more active as adults than those born co-twin with females (Fitzgerald et al, 1993), we reviewed the birth records of all the rams included in this study. Of the six male-oriented rams studied, two were born as singletons, two as twins, two as triplets. Three of the female-oriented rams were born as singletons, and four as twins. No obvious relationship was found between the number of offspring developing in utero or the sex of these offspring to sexual orientation in adulthood.

\section{Behavioural data}

The results of the behavioural tests from six rams classified as male-oriented are shown in Table 1. Each ram was given a $30 \mathrm{~min}$ test which was repeated at least three times in the preference protocol described previously. Data from two preference tests designated trials 1 and 2 in Table 1 are presented. Behavioural end points of the male-oriented rams that differed significantly $(P<0.05)$ depending on the sex of the stimulus animal were: sniffs, foreleg kicks, vocalizations and mounts. 
Table 1. Reproductive behaviours of rams classified as male-oriented in partner preference tests ${ }^{a}$

\begin{tabular}{lcccccr}
\hline & \multicolumn{5}{c}{ Number of responses per trial (mean \pm SEM) } \\
\cline { 2 - 7 } $\begin{array}{l}\text { Partner } \\
\text { preference }\end{array}$ & Sniffs & $\begin{array}{c}\text { Foreleg } \\
\text { kicks }\end{array}$ & Vocalizations & Flehmen & Mounts & Ejaculations \\
\hline Male stimulus & & & & & & \\
Trial 1 & $14.8^{*}$ & $16.7^{*}$ & $12.8^{*}$ & 00.6 & $17.3^{*}$ & 00.2 \\
& \pm 2.5 & \pm 7.5 & \pm 6.4 & \pm 0.6 & \pm 7.9 & \pm 0.2 \\
Trial 2 & $7.0^{*}$ & $10.8^{*}$ & $10.3^{*}$ & 0 & $5.5^{*}$ & 0.4 \\
& \pm 1.7 & \pm 1.8 & \pm 1.5 & 0 & \pm 1.9 & \pm 0.4 \\
Female stimulus & & & & & & \\
Trial 1 & 4.5 & 0 & 0.2 & 0 & 0 & 0 \\
Trial 2 & \pm 2.6 & 0 & 0.2 & 0 & 0 & 0 \\
& 0 & 0 & 0 & 0 & 0 & 0 \\
& 0 & 0 & 0 & 0 & 0 & 0 \\
\hline
\end{tabular}

-Animals that did not mount females in, at least, six nonpreference behavioural tests (designated Preliminary Tests in the text) were tested further. Behaviours from the last two preference tests (designated Trials) were recorded during exposture for $30 \mathrm{~min}$ to both males and females. The last trial was conducted 5 days before the subjects were killed. $n=6$ rams ${ }^{*} P<0.05$, response to males compared with response to females. (Data reprinted from Resko ef al., 1996 Biology of Reproduction 55 120-126, with permission).

Table 2. Serum steroid concentrations of rams as a function of sexual orientation

\begin{tabular}{|c|c|c|c|c|c|c|}
\hline \multirow[b]{2}{*}{ Treatment } & \multirow[b]{2}{*}{$n$} & \multicolumn{5}{|c|}{ Steroids (pg ml-1 serum) } \\
\hline & & $\mathrm{T}$ & DHT & $\Delta^{4}$ & $E_{1}$ & $\mathrm{E}_{2}$ \\
\hline Female-oriented & 7 & $\begin{array}{r}1559 \\
+228\end{array}$ & $\begin{array}{l}103 \\
\pm 45\end{array}$ & $\begin{array}{l}245 \\
\pm 67\end{array}$ & $\begin{array}{l}46 \\
+2\end{array}$ & $\begin{array}{l}15 \\
\pm 3\end{array}$ \\
\hline Male-oriented & 6 & $\begin{array}{c}874^{*} \\
\pm 196\end{array}$ & $\begin{array}{r}50 \\
\pm 10\end{array}$ & $\begin{array}{l}127 \\
\pm 61\end{array}$ & $\begin{array}{l}40^{4} \\
\pm 2\end{array}$ & $\begin{aligned} & 8^{*} \\
& \pm 1\end{aligned}$ \\
\hline
\end{tabular}

Values are means $\pm \mathrm{SEM}$, $\mathrm{T}$, testosterone; $\mathrm{DHT}$, dihydrotestosterone; $\Delta^{4}$, androstenedione, $\mathrm{E}_{1}$, oestrone; $\mathrm{E}_{2^{\prime}}$ oestradiol *Significantly different from female-oriented rams, $P<0.05$.

(Data reprinted from Resko ct al., 1996 Biology of Reproitucfion 55 120-126, with permission).

The Flehmen response and the ejaculations did not differ significantly. It is important to remember that the six males for which data are provided in this table were given at least six sexual behaviour performance tests with oestrous females over two years before the preference tests. In none of these tests were these rams interested in females.

\section{Tissue collection}

Rams were killed in random order 5 days after the last preference test. Brains were quickly removed and the various areas dissected according to previously published procedures (Moss et al., 1980). Brain areas, pituitaries, prostates and testes were rapidly frozen on dry ice. Tissue and serum samples were coded and the code was not broken until after all the samples were assayed.

\section{Steroid radioimmunoassays and gonad incubations}

Steroids were quantified by specific radioimmunoassays after chromatography on Sephadex LH-20 columns as described by Resko et al. (1980). Steroid biosynthesis by the testes in vitro was 
Table 3. Biosynthesis of steroids from $\left[{ }^{3} \mathrm{H}\right]$ progesterone by ram testicular homogenates ${ }^{\mathrm{a}}$

\begin{tabular}{llcc}
\hline & & \multicolumn{2}{c}{$\mu$ mole $\mathrm{mg}^{-1} \mathrm{~h}^{-1}$} \\
\cline { 3 - 4 } Treatment & $n$ & Testosterone & $17 \mathrm{OH}$-progesterone \\
\hline Female-oriented & 7 & $28.8 \pm 8.1$ & $416.9 \pm 100.8$ \\
Male-oriented & 6 & $12.1 \pm 2.3^{*}$ & $186.3 \pm 30.7^{*}$ \\
\hline
\end{tabular}

See Resko et al. (1996) for details of incubations and isolation of steroid metabolites. Values are means \pm SEM. * Significantly different from female-oriented rams, $P<0.05$. (Data reprinted from Resko ct $n l, 1996$ Biology of Reproduction 55 120-126, with permission).

(a)

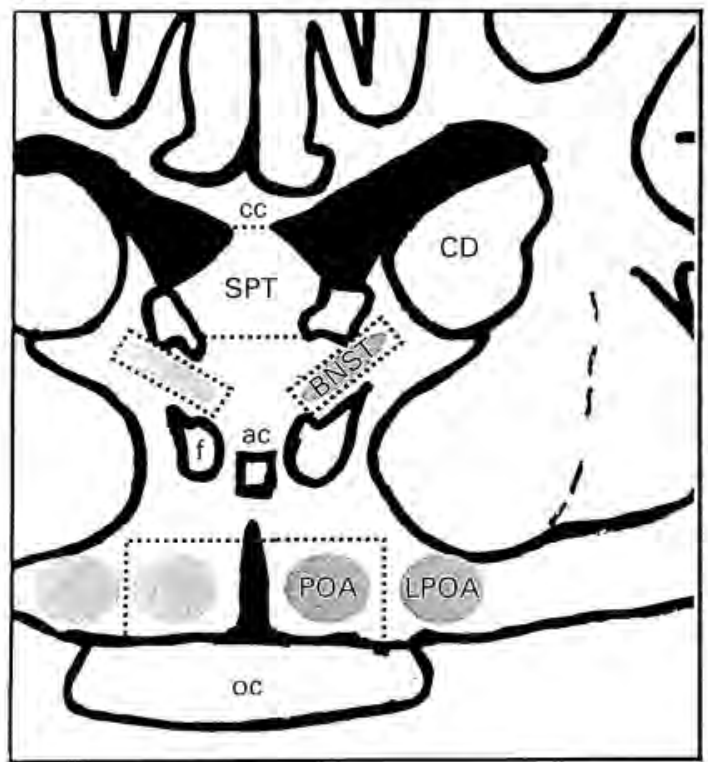

(b)

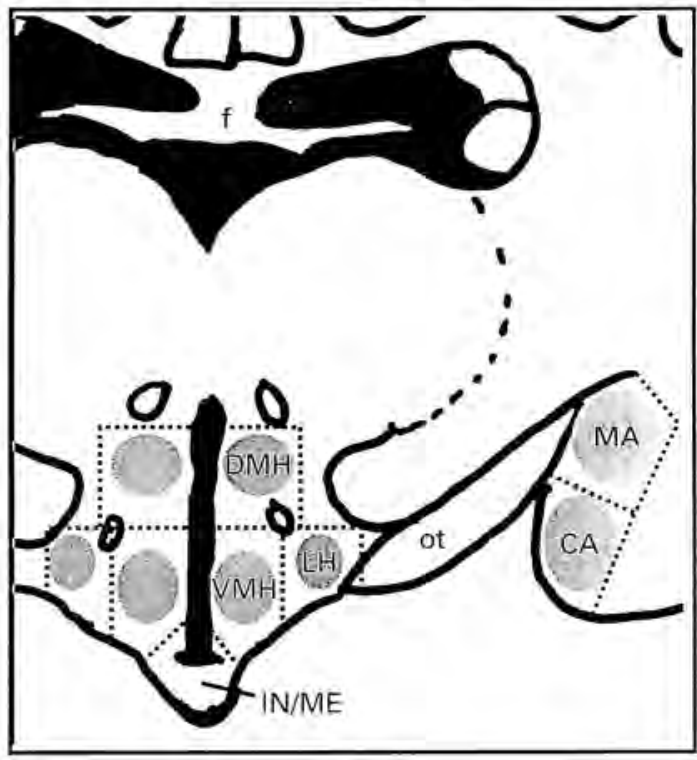

Fig. 3. Tracings of frontal sections of the adult ram brain at two levels. (a) A section at the preoptic-anterior hypothalamus; (b) a section at the medial hypothalamus. cc: corpus callosum; CD: caudate nucleus, SPT: septum; BNST: bed nucleus of the stria terminalis; ac: anterior commissure; f: fornix; POA: preoptic area-anterior hypothalamus; LPOA: lateral preoptic area-anterior hypothalamus; oc: optic chiasma; DMH: dorso-medial hypothalamus; VMH; ventro-medial hypothalamus; LH: lateral hypothalamus; IN/ME: infundibulum/median eminence; ot: optic tract; CA: cortical amygdala; and MA: medial amygdala.

determined by the method described by Resko et al. (1996). Serum steroid concentrations of rams as a function of sexual orientation are shown in Table 2. Sera from female-oriented rams contained significantly higher $(P<0.05)$ concentrations of testosterone, oestrone and oestadiol than sera from male-oriented rams. Androstenedione and 5 $\alpha$-dihydrotestosterone did not differ significantly between groups.

The capacity of testicular homogenates from male- and female-oriented rams to biosynthesize testosterone and $17 \alpha$-hydroxyprogesterone from tritiated progesterone in vitro was tested (Table 3 ). Under the same experimental conditions, the testes of male-oriented rams possessed a reduced capacity for hormone biosynthesis compared with the testes of female-oriented controls. These results taken together indicate that partner preference behaviour is correlated with steroid 
Table 4. The effects of castration on aromatase activity in the medial preoptic-anterior hypothalamus of the heterosexual ram

\begin{tabular}{lcc}
\hline Treatment & $n$ & $\begin{array}{c}\text { Aromatase activity } \\
\text { (fmol }{ }^{3} \mathrm{H}_{2} \mathrm{O} \mathrm{h}^{-1} \mathrm{mg}^{-1} \text { protein) }\end{array}$ \\
\hline Intact & 3 & $211.4 \pm 30.6$ \\
Castrated & 3 & $102.9 \pm 13.5 *$ \\
\hline
\end{tabular}

n, number of animals "Significantly different from intact value, $P<0,02$.

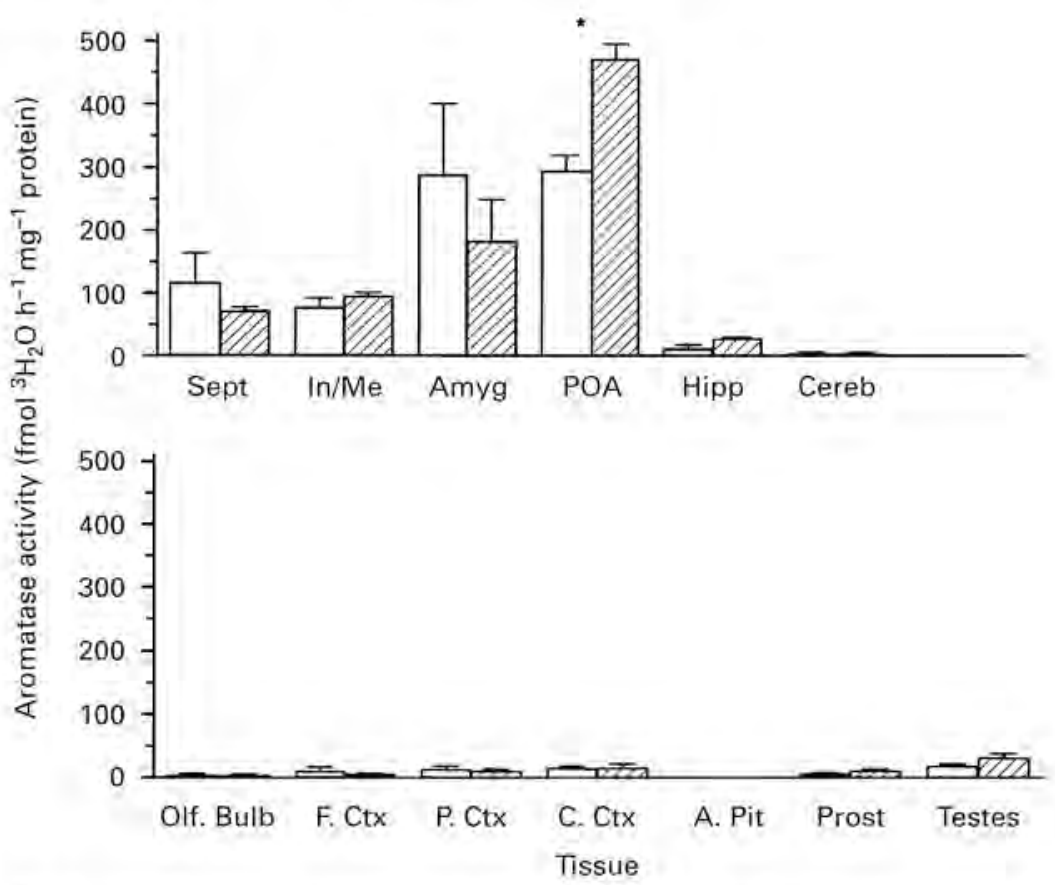

Fig. 4. Distribution of aromatase acfivity in brain, anterior pituitary gland, prostate and testis of intact $(\square)$ male-oriented $(n=6)$ and $(\square)$ female-oriented $(n=7)$ rams. Data are presented as means $\pm S E M$. ${ }^{*}$ Significant effect of sexual orientation on aromatase activity $(P<0.05)$. Sept: septum; In $/ \mathrm{Me:}$ infundibulum/median eminence; Amyg: amygdala; POA: preoptic area; Hipp: hippocampus; Cereb: cerebellum; Olf- Bulb: olfactory bulb; F. Ctx: frontal cortex; P. Ctx: parietal cortex; C. $\mathrm{Ctx}$ : cingulate cortex; A. Pit: anterior pituitary gland; Prost: prostate. (Data reprinted from Resko et al., 1996 Biology of Reproduction 55 120-126, with permission).

production by the ram testes and that male-oriented behaviour is displayed by those animals whose testes produce less hormone.

\section{Aromatase assays}

Brain aromatase activity was assayed using a ${ }^{3} \mathrm{H}_{2} \mathrm{O}$ assay as described by Roselli et al. (1984) and validated for the ram by Resko et al. (1996). A diagrammatic representation of a frontal view of the ram brain at two levels, at the level of the preoptic/anterior hypothalamus and at the level of the medial hypothalamic area (Fig. 3) can be used to locate the areas of the ram brains represented by 
data depicted in Fig. 4 and Table 4. A comparison of aromatase activity among different brain parts and between male- and female-oriented rams is shown in Fig. 4. The brains of male-oriented rams contained reduced amounts of aromatase activity only in the POA. This is the brain area usually associated with the mediation of sexual behaviour in many mammalian species.

The effects of castration on aromatase activity in the POA of brains from heterosexual rams (Table 4; Roselli et al., 1998) show that castration significantly reduced the amount of aromatase activity in this region $(P<0.02)$ adding to the list of species in which castration or androgen control aromatase activity. A corollary to the above is the fact that castration not only reduces reproductive behaviours in female-oriented rams but also did so in male-oriented rams. (Pinckard et al., 1998). These results seem to imply that male-oriented behaviour in this species is androgen-dependent or alternatively is regulated by a product of the testes.

\section{Conclusions}

The rationale for studying male-oriented behaviour in rams is twofold. First, from the point of view of animal husbandry, these rams are 'behaviourally infertile' and, therefore, constitute a liability to breeders who cannot determine this fact before purchase. Second, further research may identify this species as a model for the study of male-oriented behaviour in general. In the former case, an understanding of the role of in situ oestrogen formation in the preoptic-anterior hypothalamic area of the brain may lead to endocrine therapies that may be effective for improving the reproductive success of these animals. In the latter case, examination of the defects in testicular androgen production in male-oriented rams may ultimately lead to studies of the fetal testes and a better understanding of the unresolved complexities of the nature versus nurture origins of maleorientation of males in a wide variety of species.

\section{References}

Allen LS and Gorski RA (1992) Sexual orientation and the size of the anterior commissure in the human brain Proceedings of the National Acadeny of Sciences USA 89 7199-7202

Attal ] (1969) Levels of téstosterone, androstenedione, estrone and estradiol-17 $\beta$ in the testes of fetal sheep Endocrinology $85280-289$

Bakker J, Ophemert JV and Slob AK (1993) Organization of partner preference and sexual behavior and its nocturnal rhythmicity in male rats Behavioral Neuroscience 107 $1049-1058$

Banks EM (1964) Some aspects of sexual behaviour in domestic sheep, Ovis aries. Beluaviour 23 249-279

Baum MJ, Tobet SA, Cherry JA and Paredes RG (1996) Estrogenic control of preoptic area development in a carnivore, the ferret Celluilar and Molecular Neurobiology 16 117-128

Beach FA (1976) Sexual attractivity, proceptivity; and receptivity in female mammals Hormones and Behnorour 7 $105-138$

Beyer C, Morali G, Naftolin F, Larsson K and Perez-Palacios G (1986) Effect of some antiestrogens and aromatase inhibitors on androgen induced sexual behavior in castrated male rats Hormones and Behaviour 7 353-363

Dagg AT (1984) Homosexual behavior and female-male mounting in mammals - a first survey Manmmal Revicw 14 $155-185$

Davidson JM (1969) Effects of estrogen on the sexual behavior of male rats Endocrinology 84 1365-1372

Dohler KD, Srivastava SS, Shryne JE, Jarzab B, Sipos A and Gorski RA (1984) Differentiation of the sexually dimorphic nucleus in the preoptic area of the rat brain is inhibited by postnatal treatment with an estrogen antagonist Neuroendocrinology 38 297-301

Dorner G, Rohde W, Stahl E, Kreel L and Masius WG (1975) A neuroendocrine predisposition for homosexuality in men Archives Sexual Behaviour 4 1-8

Everitt BJ and Stacey P (1987) Studies of instrumental behavior with sexual reinforcement in male rats (Rathis norvegicus): II. Effects of preoptic area lesions, castration, and testosterone fournal of Comparative Psychology $101407-419$

Fitzgerald JA, Ruggles AJ Stellflug JN and Hansel W (1985) A seven-day synchronization method for ewes using medroxyprogesterone acetate (MPA) and prostaglandin $\mathrm{F}_{20}$ Journal of Aximal Science 61 466-469

Fitzgerald JA, Perkins A and Hemenway K (1993) Relationship of sex and number of siblings in utere with sexual behavior of mature rams Applied Animal Beltavior Science 38 283-290

Freije D, Helms C, Watson MS and Donis-Keller H (1992) Identification of a second pseudoautosomal region near the $X_{q}$ and $T q$ telomeres Sicience 258 1784-1786

Freud S (1953) Three essays on the theory of sexuality. In Stondard Edition of the Complete Psychological Works of Sigmund Freud pP 125-143 Anonymous Hogarth Press, London

Geist V (1971) Mountain Sheep: A Study In Behavior Aud Evolution p 139 University of Chicago Press, Chicago IL.

Giantonio GW, Lund NL and Gerall AA (1970) Effect of diencephalic and rhinencephalic lesions on the male rat's sexual behavior Journal of Comparative Physiology and Psychology 73 38-46

Ginton A and Merari A (1977) Long range effects of MPOA 
lesions on mating behavior in the male rat Brain Research $120158-163$

Gladue BA (1984) Neuroendocrine response to estrogen and sexual orientation Science 28 1496-1499

Hamer DH, Hu S, Magnuson VL, Hu N and Pattatucci AML (1993) A linkage between DNA markers on the X chromosome and male sexual orientation Science 261 321-327

Hart BL (1986) Medial preoptic-anterior hypothalamic Jesions and sociosexual behavior of male goats Physiology and Behation 36 301-305

Hart BL (1989) Medial preoptic-anterior hypothalamíc area and sociosexual behavior of male dogs: a comparative and nẹuropsychological analysis Journal of Comparatize Physiology and Psychology 86 328-349

Hart BL, Haugen CM and Peterson DM (1973) Effects of preoptic-anterior hypothalamic lesions on mating behavior in male cats Brain Research 54 177-191

Heimer L and Larsson K (1966) Impairment of mating behavior in male rats following lesions in the preoptic-anterior hypothalamus continuum Brain Resenrch 3 248-263

Hu S, Pattatucci AML, Patterson C, Li L, Fulker DW, Cherny SS, Kruglyak L and Hamer DH (1995) Linkage between sexual orientation and chromosome $\mathrm{Xq} 28$ in males but not in females Nature Genetics 11 248-256

Karsch FJ and Foster DL. (1975) Sexual differentiation of the mechanism controlling the preovulatory discharge of luteinizing hormone in sheep Endocrinology 97 373-379

Le Vay S (1991) A difference in hypothalamic structure between heterosexual and homosexual men Science 253 1034-1037

Lindsay DR (1961) Studies on the efficiency of mating in the sheep II. The effects of freedom of rams, paddock size, and age of ewes fournal of Agricultuml Science 57 141-145

Lindsay DR (1966) Modification of behavioral oestrus in the ewe by social and hormonal factors Animal Belunviour 14 73-83

McEwen BS, Lieberburg 1, Chaptal C and Krey LC (1977) Aromatization: important for sexual differentiation of the neonatal rat brain Hormones and Behavior $9249-263$

MacLusky NJ and Naftolin F (1981) Sexual differentiation of the central nervous system. Sciencè 211 1294-1302

Moss GE, Adams TE, Niswender GD and Nett TM (1980) Effects of parturition and suckling on concentrations of pituitary gonadotropins, hypothalamic GnRH and pituitary responsiveness to GnRH in ewes Journal of Animal Science $50496-502$

Page DC, Mosher R, Simpson EM, Fisher MC, Mardon G, Pollack J, McGillivary B and de la Chapelle A (1987) The sex-determining region of the human $\mathrm{Y}$ chromosome encodes a zinc finger protein Cell 51 1091-1104

Paredes RG and Baum MJ (1995) Altered sexual partner preference in male ferrets given exitotoxic lesions of the preoptic area anterior hypothalamus Journal of Nenroscience $156619-6630$

Pepelko WE and Clegg MT (1965) Influence of season of the year upon patterns of sexual behavior in male sheep Journal of Animal Science 24 633-637

Perkins A and Fitzgerald JA (1992) Luteinizing hormone, testosterone and behavioral response of male-oriented rams to estrous ewes and rams joumal of Animal Science 70 $1787-1794$
Perkins A, Fitzgerald JA and Moss GE (1995) A comparison of LH secretion and brain estradiol receptors in heterosexual and homosexual rams and female sheep Hormones and Behavior. 29 $31-41$

Phoenix CH, Goy RW, Gerall AA and Young WC (1959) Organizing action of prenatally administered testosterone propionate on the tissue mediating mating behavior in the female guinea pig Endocrinology 65 369-382

Pinckard K, Stellflug J, Williams M and Stormshak F (1998) Influence of castration and estrogen replacement on sexual behavior in asexual, heterosexual and male-oriented rams Biology of Reproduction (Supplement 1) 58 (Abstract)

Pomerantz DK and Nalbandov AV (1975) Androgen level in the sheep fetus during gestation Proccedings of the Society for Experimental Biology and Medicine 149 413-416

Resko JA (1985) Gonadal hormones during sexual differentiation in vertebrates. In Handhook of Behavioral Neurobiology pp 21-42 Eds. N Alder, D Pfaff, and RW Goy. Plenum Publishing Corporation, New York

Resko IA, Ellinwood WE, Pasztor LM and Buhl AE (1980) Sex steroids in the umbilical circulation of fetal rhesus monkeys from the time of gonadal differentiation Journal of Clinical Endocrinology and Metabolism 50 900-905

Resko JA, Perkins A, Roselli CE, Fitzgerald JA, Choate JVA and Stormshak F (1996) Endocrine cortelates of partner preference behavior in rams Biology of Reproduction $\mathbf{5 5}$ 120-126

Roselli CE, Ellinwood WE and Resko JA (1984) Regulation of brain aromatase activity in rats Endocrinology 114 192-200

Roselit CE, Horton LE and Resko JA (1985) Distribution and regulation of aromatase activity in the rat hypothalamus and limbic system Endocrinology $1172471-2477$

Roselli CE, Stormshak F and Resko JA (1998) Distribution and regulation of aromatase activity in the ram hypothalamus and amygdala Brain Research 811 105-110

Ryner LC, Goodwin SF, Castrillon DH, Anand A, Villella A, Baker BS, Hall JC, Taylor BJ and Wasserman SA (1996) Control of male sexual behavior and sexual orientation in Drosop/üla by the fruitless gene Cell 87 1079-1089

Short RV (1974) The Sexual Endocrinology of the Perinatal Periont pP 121 Eds MG Forest and J Bertrand. INSERM Colloque International, Lyon

Slimp JC, Hart BL and Goy RW (1978) Heterosexual, autosexual and social behavior of adult male rhesus monkeys with medial preoptic-anterior hypothalamic lesions Brain Research 142 105-122

Sodersten P (1978) Effects of anti-oestrogen treatment of neonatal male rats on lordosis behaviour and mounting behaviour in the adult Journal of Endocrinology 76 241-249

Solari AJ (1980) Synaptonemal complexes and associated structures in microspread human spermatocytes Chromosoma 81 315-337

Swaab DF and Hofman MA (1990) An enlarged suprachiasmatic nucleus in homosexual men Brain Research 537 141-148

Zenchak JJ, Anderson GC and Schein MW (1981) Sexual partner preference of adult rams (Otis aties) as affected by social experiences during rearing Applied Animal Ethology 7 $157-167$ 